\title{
Avaliação dos efeitos de tensões residuais através da remoção de material
}

\section{Evaluation of residual stress effects by means of material removal}

Alexandre da Silva Rocha

Prof. Dr. Eng. Laboratório de Transformação Mecânica, Departamento de Metalurgia, UFRGS Av. Bento Gonçalves, 9500, Agronomia Porto Alegre, RS, Brasil CEP 91501-970 alexandre.rocha@ufrgs.br

Rafael Menezes Nunes M.Sc. Eng. Laboratório de Transformação Mecânica, Departamento de Metalurgia, UFRGS Av. Bento Gonçalves, 9500, Agronomia Porto Alegre, RS, Brasil CEP 91501-970 rafael.nunes@ufrgs.br

Eduardo Moller Ferlauto Eng. Mecânico, Laboratório de Transformação Mecânica, Departamento de Metalurgia, UFRGS Av. Bento Gonçalves, 9500, Agronomia Porto Alegre, RS, Brasil CEP 91501-970 ferlautoeduardo@terra.com.br

\section{Resumo}

As tensões residuais impostas durante o processo de manufatura de um componente são um dos maiores potenciais para o aparecimento de distorções. Neste trabalho os experimentos concentraram-se nas mudanças dimensionais de barras de aço após a remoção de material, esta remoção foi realizada objetivando-se estimar as tensões residuais presentes nas barras em conseqüência do processo de fabricação. A remoção de material foi realizada após cada etapa do processo de fabricação. As amostras foram retiradas de cinco diferentes estágios da trefilação combinada, sendo elas: pré-endireitamento, jateamento, trefilação, endireitamento e polimento por rolos cruzados ("PERC"). No último estagio houve variações no ângulo entre os rolos: $16^{\circ}, 17^{\circ}$ e $18^{\circ}$. As remoções de material foram realizadas de nodo a deixar uma parcela correspondente a uma profundidade de $1 / 6$ ou $1 / 2$ do diâmetro da barra. Os cortes foram realizados em diferentes posições angulares para caracterizar heterogeneidades impostas durante o processo $\left(0^{\circ}, 90^{\circ}, 180^{\circ}, 270^{\circ}\right)$. Devido à remoção de material as tensões residuais são rearranjadas na parte restante que conduz ao

\section{Abstract}

The residual stresses imposed during the manufacturing process of a component are one of the main potential carriers for the appearance of distortion. In this work experiments concerning dimensional changes of bars after material removal were carried out in order to estimate the residual stress level stored as a consequence of the manufacturing route. The material removal was accomplished after each processing step. The samples were taken after five different steps of a combined colddrawing: pre-straightening, shot-blasting, cold-drawing, straightening and polishing by crossed rolls. The last step was varied according to the angles between crossed rolls: $16^{\circ}, 17^{\circ}$ and $18^{\circ}$. The material removal was accomplished in such a way to leave a material portion corresponding to a depth of $1 / 6$ or $1 / 2$ of the diameter of the bar. The cuts were done at different angular positions to characterize imposed peripheral inhomogeneities $\left(0^{\circ}, 90^{\circ}, 180^{\circ}, 270^{\circ}\right)$. Due to the material removal, the residual stresses will be rearranged in the remaining part, which leads to the appearance of a deflection of the remaining material. This bending was used to try to estimate the residual stress levels previously present in the bars. 
aparecimento de uma deflexão do material restante. Esta deflexão foi usada para estimar os níveis de tensão residuais presente previamente nas barras.

Palavras-chave: trefilação combinada, tensões residuais, métodos de deflexão.
Key words: cold-drawing, residual stress, deflection methods.

\section{Introdução}

Com o desenvolvimento industrial cada vez mais é necessário o conhecimento dos parâmetros de processamento do material durante a rota de fabricação e bem como a sua influência no produto final. $O$ controle e conhecimento destes parâmetros permitem a estabilidade do processo produtivo, desta forma, podem-se solucionar problemas inesperados durante o processo de fabricação com mais eficiência e velocidade. No processo de trefilação uma importante fonte de perdas durante o processamento do material são as distorções indesejadas, e estas distorções são relacionadas ao nível de tensões residuais no material.

A trefilação pode ser definida como sendo um processo de fabricação por deformação plástica na qual há um tracionamento do fio-máquina (matéria-prima) através da ferramenta (fieira), ocasionando assim uma redução de área na seção transversal e aumento de comprimento. Uma das características principais do processo de trefilação é o excelente acabamento superficial e também a ótima precisão dimensional. A principal matéria-prima usada na trefilação de barras é o fio-máquina. As grandes vantagens do processo de trefilação são: ganho de resistência mecânica, acabamento superficial e a alta velocidade do processo (Dieter, 1986).

As tensões residuais podem favorecer de forma benéfica ou maléfica os componentes mecânicos, em geral tensões residuais compressivas na superfície são mais favoráveis, pois aumentam a vida em fadiga de um componente mecânico. O oposto ocorre com tensões residuais trativas, pois diminuem a vida em fadiga.

No processo de trefilação combinada, o controle das tensões residuais está relacionado ao controle de distorções das barras durante o processo de trefilação, ou ainda, em etapas subseqüentes de processamento, como por exemplo: usinagem e tratamentos térmicos. Este controle de distorções é muito importante para diminuir custos de processo aumentando a competitividade do produto, desta forma, diminuindo etapas de endireitamentos que requerem um alto tempo de processamento conseqüentemente aumentando o custo do produto final.

As tensões residuais presente em um material sempre estará em equilíbrio, a soma das tensões totais trativas e compressivas no corpo sempre será zero, assim, plotando-se uma curva das tensões trativas e compressivas presentes no material a soma das forças e momentos será zero. Na prática a determinação destas curvas é complexa, pois o estado de tensões apresentado no material é tridimensional (Lu, 1996).

As tensões residuais apresentam um caráter elástico, assim, o valor máximo que estas tensões podem atingir é a tensão de escoamento local do material. Também se define as tensões residuais como 
sendo ordinárias, ou seja, uma tensão trativa irá somar-se com outra tensão trativa, ou ainda, uma tensão trativa irá subtrair-se com outra tensão compressiva e vice-versa. As tensões residuais podem ser aliviadas aquecendo o material até uma temperatura a qual a tensão de escoamento do material é igual ou inferior às tensões residuais presentes no material. Ou seja, neste caso as tensões residuais irão causar deformações plásticas, escoamento do material e serão aliviadas (Lu, 1996).

As tensões residuais podem ser medidas por diferentes métodos, dentre eles destacam-se os métodos de slitting (deflexão), hole-drilling, difração de raios-X, difração de nêutrons, micro-magnético dentre outros. Cada método apresenta suas aplicações, vantagens, desvantagens e peculiaridades. O método de slitting (deflexão), ou ainda, o método de remoção de material apresenta como principal vantagem o baixo custo para a sua realização, pois não é necessário o uso de equipamentos sofisticados, como por exemplo, um difratômetro de raios-X, porém a correlação entre a deflexão causada pela remoção de material e o cálculo do nível de tensões residuais apresentados nem sempre é simples implicando em formulações complexas. Entretanto o método de remoção pode ser usado de forma qualitativa, apenas mostrando se o comportamento de tensões residuais é compressivo ou trativo, como demonstrado neste trabalho, desta forma ele apresenta ótimos resultados e simplicidade para análise.

Primeiramente, para a determinação de tensões residuais é necessário classificar qual tipo de tensão está sendo medido pelo método (Walton, 2002). Podemos classificar as tensões residuais como macroscópicas tipo I e microscópicas do tipo II e tipo III. As tensões macroscópicas são as tensões residuais que se distribuem em larga escala e se equilibram por todo o componente. Na classificação das tensões residuais macroscópicas considera-se o material como sendo homogêneo e em uma visão macroscópica e são as tensões medidas por métodos de dissecção do material, como por exemplo, hole-drilling e métodos secção, como por exemplo, o método utilizado neste trabalho. As tensões residuais do tipo II e III também chamadas de microscópicas são formadas pela não homogeneidade da estrutura cristalina do material. Estas tensões residuais estão associadas ao domínio cristalino do material, como por exemplo, o grão e também fases presentes no material e estas tensões estão relacionadas ao balanço entre diferentes grãos ou fases presentes no material. As tensões residuais microscópicas do tipo III existentes na escala atômica, correspondente à ação criada por todos os diferentes tipos de defeitos cristalinos.

O método de medição de tensões residuais a partir da remoção de material baseia-se no equilíbrio da distribuição de tensões no material e ao principio de superposição de tensões (Lu, 1996). Baseando-se como modelo um cilindro de aço maciço com distribuição de tensões residuais trativas na superfície e tensões residuais compressivas no núcleo. Fazendo-se a remoção de material deste cilindro, conforme a Figura 1 ocorrerá um novo estado de tensões e a partir deste novo estado de tensões de acordo com o nível de tensões residuais o material poderá empenar. 


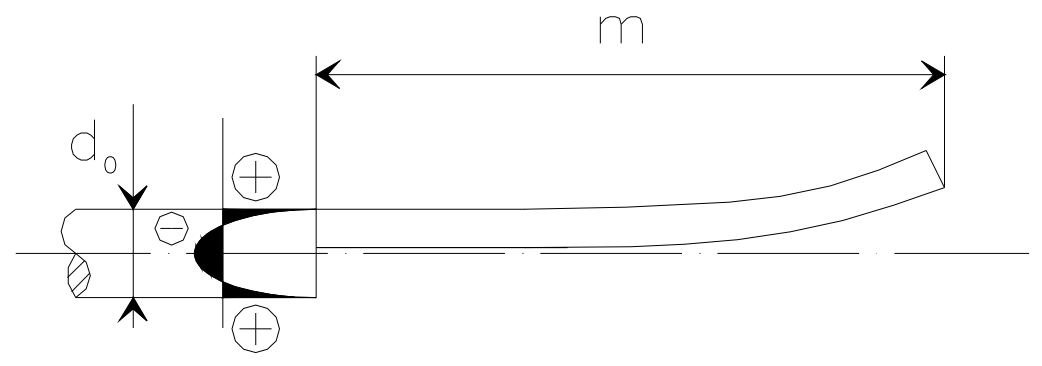

Figura 1: Exemplo de uma remoção de material para caracterização de tensões residuais em uma barra cilíndrica.

As tensões residuais trativas na superfície deste cilindro estão forçando o material a ocupar um volume maior do que a que está sendo ocupado. Por outro lado, as tensões residuais compressivas no núcleo do material estão forçando este material a ocupar um volume menor do que a que está sendo ocupado no momento, porém todo este estado de tensões está em equilíbrio, e assim o material mantém a sua forma. Após a remoção de material o que ocorre é uma redistribuição de tensões residuais no material, e assim, as tensões residuais saem do equilíbrio, desta forma, há então um re-equilíbrio de tensões no material, fazendo-se que ele deforme plasticamente para aliviar as tensões sobressalentes. Neste caso em especifico, a deformação ocorre de forma que o material superficial tenderá a ocupar uma área maior e assim este irá "abrir" (Figura 1), pois os efeitos das tensões residuais trativas na superfície sobrepõem-se ao efeito de tensões residuais compressivas do núcleo pela remoção do material. O inverso irá ocorrer em um cilindro com tensões residuais compressivas na superfície e trativas no núcleo, fazendo-se a mesma remoção de material observada na Figura 1, de forma análoga ao caso anterior, o material superficial irá "fechar", pois o efeito das tensões residuais compressivas neste caso é maior (Walton, 2002).

A trefilação combinada é composta de várias etapas e dentre as principais características de processo estão, a alta produtividade aliada ao alto grau de automação no maquinário. As principais etapas do processo de trefilação combinada são: preparação dos rolos, pré-endireitamento horizontal, préendireitamento vertical, jateamento com granalhas, trefilação, endireitamento horizontal, endireitamento vertical, operação de corte, endireitamento e polimento por rolos cruzados ("PERC"). Operações de controle de qualidade e enfeixamento. As velocidades de processamento de material podem chegar a $100 \mathrm{~m} / \mathrm{min}$. $\mathrm{O}$ material de partida é um fio-máquina laminado a quente e fornecido em forma de bobina, as principais etapas do processo de trefilação combinada analisadas neste trabalho são mostradas na Figura 2, bem como, são mostrados em vermelho os pontos de retirada de amostras.

Os parâmetros do processo de trefilação, tais como, coeficiente de atrito, geometria da fieira, velocidade de trefilação, grau de redução afetam diretamente a qualidade do produto trefilado, em especial tensões residuais longitudinais (AXIAL) podem afetar o componente por uma mudança nas dimensões ou ainda empenamentos em etapas subseqüentes de processamento, por exemplo, tratamentos térmicos ou usinagem (Asakawa et al., 2002). 


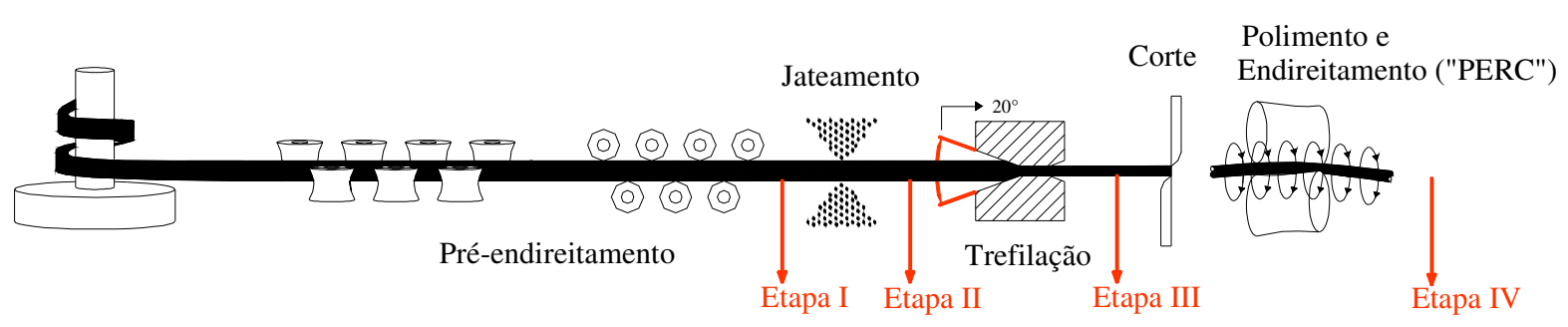

Figura 2: Principais etapas do processo de trefilação combinada.

\section{Materiais e Métodos}

As amostras analisadas foram retiradas de quatro diferentes etapas do processo de trefilação combinada (Figura 2), sendo elas: pré-endireitamento horizontal e vertical (etapa I), jateamento (etapa II), trefilação (etapa III) e polimento e endireitamento por rolos cruzados - "PERC" (etapa IV), sendo que na etapa de polimento e endireitamento por rolos cruzados ("PERC") houve variação no ângulo dos rolos. Em cada etapa foram retiradas seis amostras sendo elas:

- Pré-endireitada

- Jateada

- Trefilada

- Polimento e endireitamento por rolos cruzados ("PERC") com ângulo de $16^{\circ}$

- Polimento e endireitamento por rolos cruzados ("PERC") com ângulo de $17^{\circ}$

- Polimento e endireitamento por rolos cruzados ("PERC") com ângulo de $18^{\circ}$

Na obtenção de amostras foi levado em conta a orientação das amostras retiradas em relação a um referencial fixo no maquinário. Esta orientação é importante para correlacionar dados obtidos da caracterização do material com as tensões aplicadas durante o processo. Nos resultados obtidos verificou-se a importância da marcação no momento da retirada das amostras, pois há correlação entre os resultados obtidos nos ensaios e a posição especifica do ângulo periférico da amostra em relação ao maquinário, conforme mostrado na Figura 3. A marcação também levou em conta o ângulo e o sentido com que a barra é processada conforme mostrado na Figura 3.

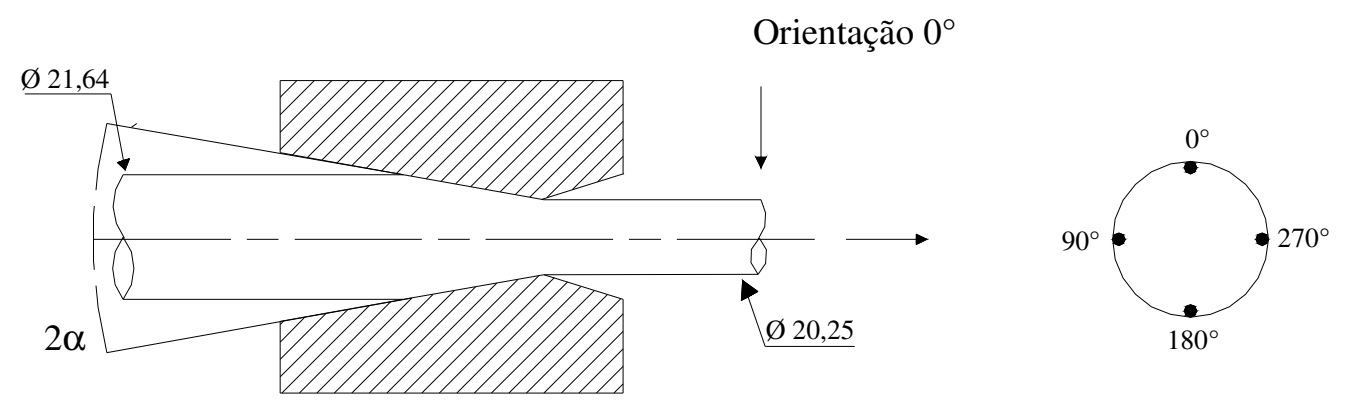

Figura 3: Sistema de marcação das amostras, vista lateral da fieira. 
A Tabela 1 mostra a análise química do material, aço ABNT 1048. O material apresenta uma estrutura ferrítico-perlítica (Figura 4) após a laminação a quente, etapa anterior a trefilação, e mantém esta estrutura após a trefilação, a dureza média do fio-máquina é de $200 \mathrm{HV}$.

Tabela 1: Análise química do aço ABNT 1048.

\begin{tabular}{|c|c|c|c|c|c|c|c|}
\hline Elemento & $\mathrm{C}$ & $\mathrm{Si}$ & $\mathrm{Mn}$ & $\mathrm{P}$ & $\mathrm{S}$ & $\mathrm{Cr}$ & $\mathrm{Fe}$ \\
\hline$\%$ & 0,43 & 0,21 & 0,73 & 0,01 & 0,02 & 0,19 & 98,05 \\
\hline
\end{tabular}

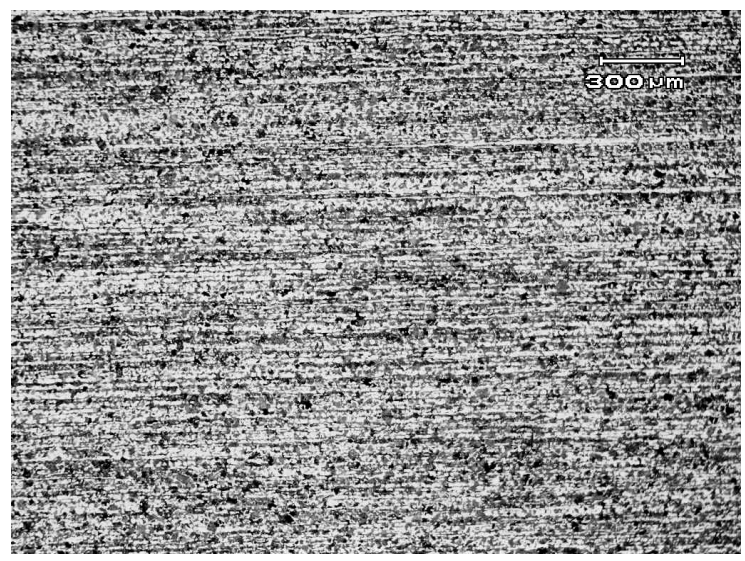

Figura 4: Fio-máquina aspecto longitudinal do fio-máquina, estrutura perlítica (região escura) e ferrita (região clara), ataque Nital 2\%, aumento 50X.

As amostras foram cortadas com $300 \mathrm{~mm}$ de comprimento e as medições de empenamento prévio das barras foram executadas em uma máquina de medição por coordenadas Mitutoyo Beyond 710, com resolução de 0,001mm. Após a medição, para a retirada de material foram realizados cortes longitudinais à uma distância 1/6 diâmetro e 1/2 diâmetro da superfície e um corte transversal a uma distância de 3,6mm e $10,82 \mathrm{~mm}$ respectivamente do topo da amostra. Nos cortes foi utilizada uma máquina de eletroerosão a fio Mitsubishi FX-10K usando-se um diâmetro de fio de 0,25mm. A utilização de um equipamento de eletroerosão para a realização dos cortes torna-se necessária para não haver influência da operação de corte no nível de tensões residuais finais. Um exemplo prático, onde o corte influenciou no nível de tensões residuais foi apresentado por (Wang e Gong, 2002), o autor afirma que o aquecimento causado por um disco de corte poderá aliviar as tensões residuais presentes no material e desta forma a deflexão apresentada após a remoção de material será menor. Cada corte longitudinal foi efetuado em uma posição periférica especifica conforme a realização da retirada de amostras levando-se em conta a orientação do maquinário mostrado na Figura 3. Após a realização dos cortes nas amostras foram realizados novamente medições de empenamento, caracterizando assim a deflexão devido à remoção de material.

Na Figura 5 são mostradas as posições periféricas das remoções realizadas, as remoções 1 a 4 foram realizados a $1 / 6$ do diâmetro inicial da amostras e as remoções 5 e 6 foram realizados a 1/2 do diâmetro inicial das amostras, sempre observando a orientação original do maquinário. 


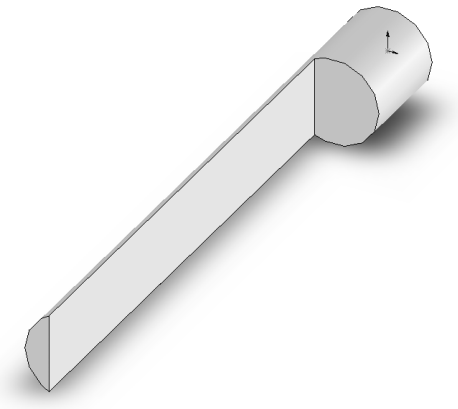

Remoção I (REM.I) - Área analisada referente a posição $90^{\circ}-1 / 6 \varnothing$

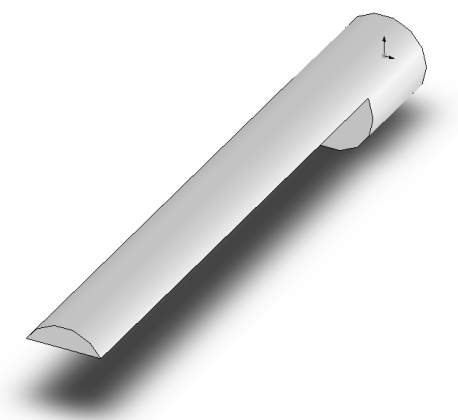

Remoção III (REM.III) - Área analisada referente a posição $0^{\circ}-1 / 6 \varnothing$

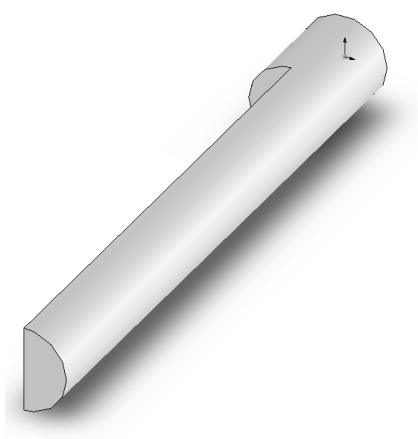

Remoção V (REM.V) - 1/2ø

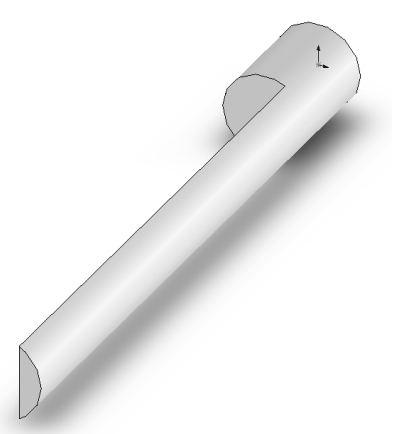

Remoção II (REM.II) - Área analisada referente a posição $270^{\circ}-1 / 6 \varnothing$

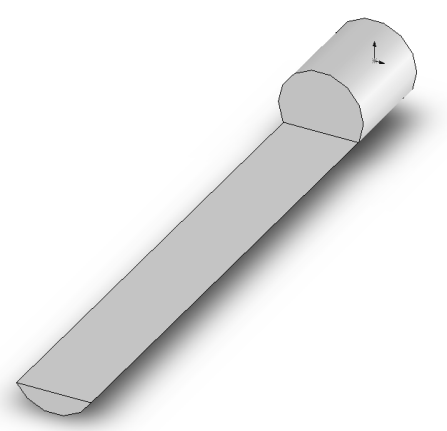

Remoção IV (REM.IV) - Área analisada referente a posição $180^{\circ}-1 / 6 \varnothing$

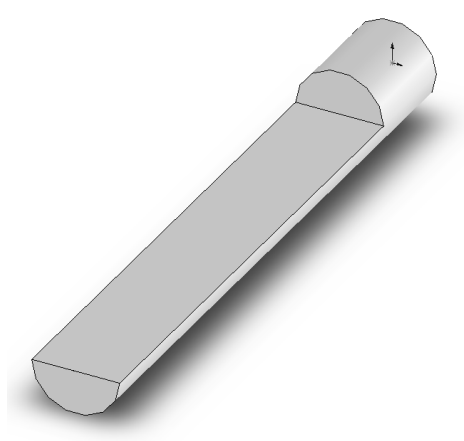

Remoção VI (REM.VI) - 1/2 ø

Figura 5: Posição periférica das remoções realizadas.

\section{Resultados e Discussão}

Após a remoção de material, as barras foram medidas para avaliar a deflexão causada e assim estimar o nível de tensões residuais médio presentes no material antes da remoção de material apresentado em cada etapa do processo. Utilizou-se nos gráficos a sigla "REM" referente à palavra remoção (Figura 6). 


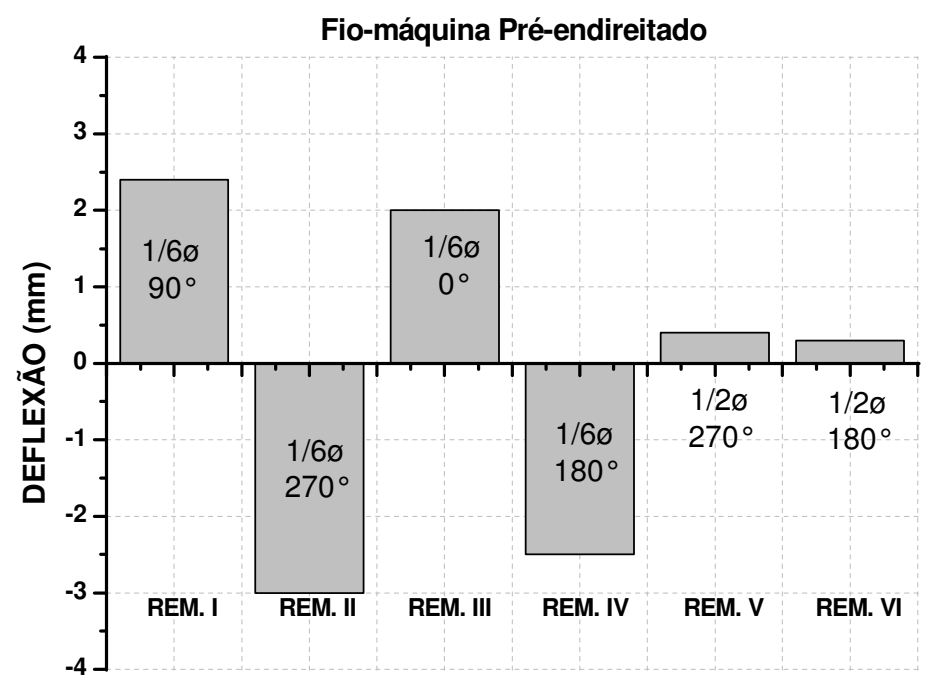

Figura 6: Deflexões apresentadas pelo fio-máquina pré-endireitado.

Na Figura 6 são mostrados os resultados para o fio-máquina pré-endireitado nota-se que há diferenças no nível e comportamento das deflexões, desta forma, as tensões residuais apresentadas na região periférica do fio-máquina após a remoção de material deixando 1/6 do diâmetro inicial da barra. Nas remoções de material 1 e 3 as tensões tem caráter trativo, nas remoções 2 e 4 as tensões apresentam-se compressivas. O principal motivo deste comportamento está na matéria-prima inicial, pois o fio-máquina é fornecido em bobinas e é necessário o pré-endireitamento deste fio-máquina para desfazer-se a curvatura da bobina e conseguinte a realização da trefilação. Para a realização do pré-endireitamento do fio-máquina é necessário a aplicação de diferentes níveis de tensões ao longo da periferia devido ao formato inicial ter uma curvatura acentuada, desta forma aplica-se tensões contrárias nos ângulos de $0^{\circ}$ e $180^{\circ}$ (posição superior e inferior da barra), assim como nas posições de $90^{\circ}$ e $270^{\circ}$ (laterais da barra) conforme pode ser visto na Figura 12 e Figura 13. As remoções 5 e $6(1 / 2 \varnothing)$ apresentam um comportamento trativo.

No fio-máquina (Figura 7) após o jateamento as tensões residuais apresentam um comportamento compressivo em toda superfície, remoções 1 a 4 (1/6 do diâmetro inicial), apresentando pequenas diferenças no nível de tensões ao longo da periferia da barra. Este comportamento também demonstrado nos trabalhos de Kennedy et al (Kennedy et al., 2005). Estas pequenas diferenças podem ser explicadas por pequenas variações do equipamento durante o processamento do material. Também observa-se a $1 / 2 \varnothing 0$ comportamento trativo ou compressivo apresentado, este comportamento pode ser explicado pela influência do pré-endireitamento (etapa anterior) (Zoch, 2006; Klein et al., 2006). 


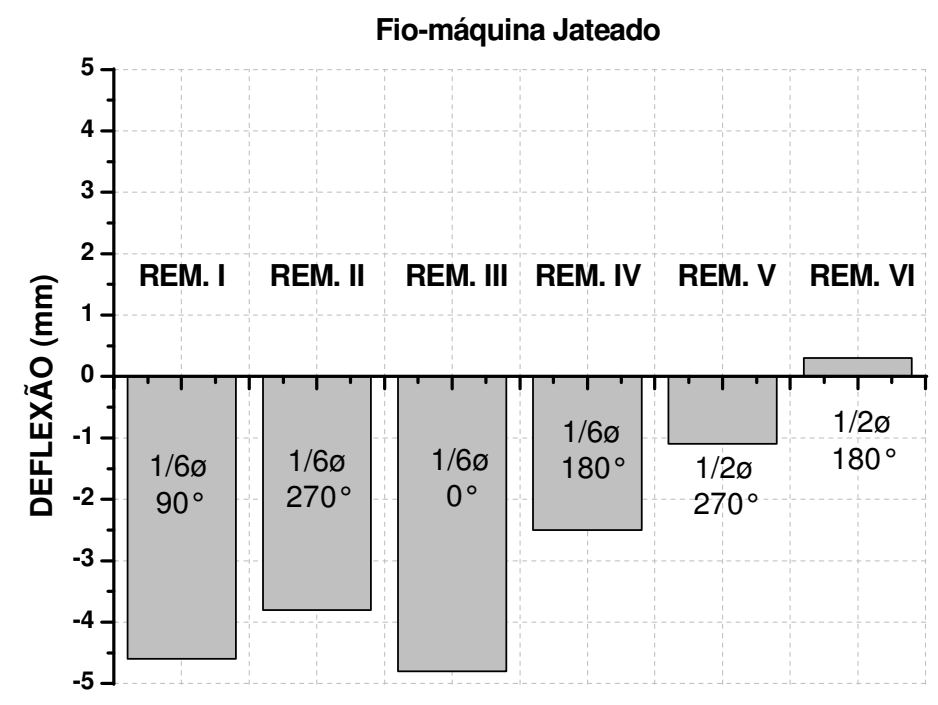

Figura 7: Deflexões apresentadas pelo fio-máquina jateado.

Na Figura 8 observa-se o comportamento apresentado pela barra trefilada, o comportamento na superfície (remoções 1 a 4) é trativo e com uma alta deflexão após o os ensaios. O comportamento do material após as remoções 5 e $6(1 / 2 \varnothing)$ demonstra a pré-existência de tensões residuais trativas. Este comportamento também foi demonstrado em outros estudos (Atienza e Elices, 2004; Akikazu et al., 2001; Wang e Gong, 2002; Asakawa et al., 2002; Metz et al., 2007).

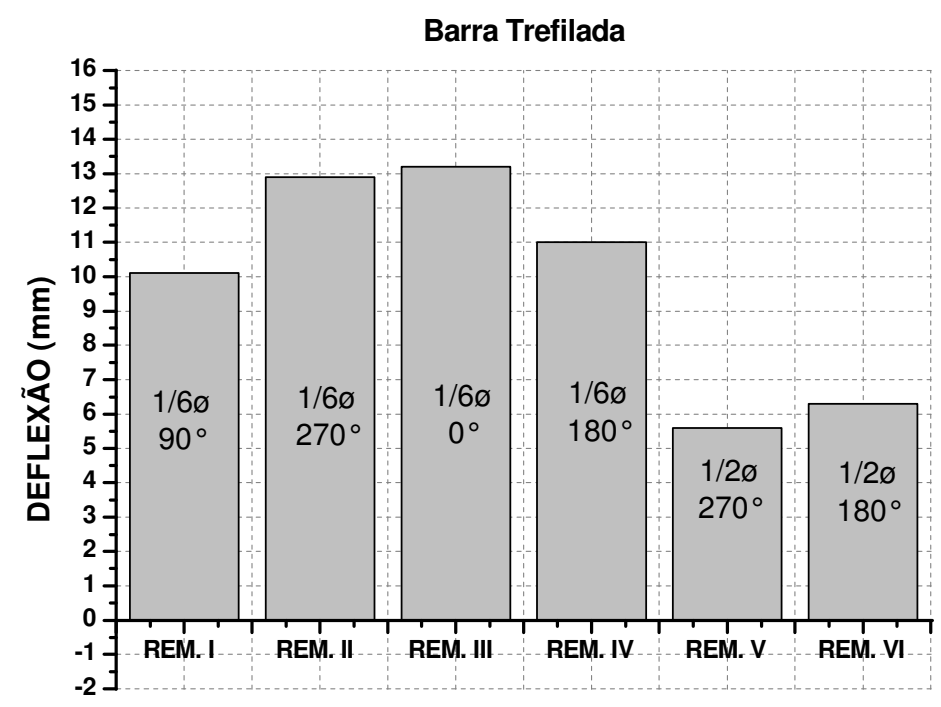

Figura 8: Deflexões apresentadas pela barra após a trefilação.

Na Figura 9 observam-se os resultados para a barra endireitada e polida por rolos cruzados ("PERC") com ângulo de $16^{\circ}$, as tensões residuais e deflexões na superfície da barra (remoções 1 a 4) apresentam caráter compressivo. Não houve grandes variações ao longo da posição periférica da barra, considerando as remoções 5 e $6(1 / 2 \varnothing)$ as tensões mudam o comportamento para trativo da mesma forma caracterizado por Wu (Wu et al., 2000). 


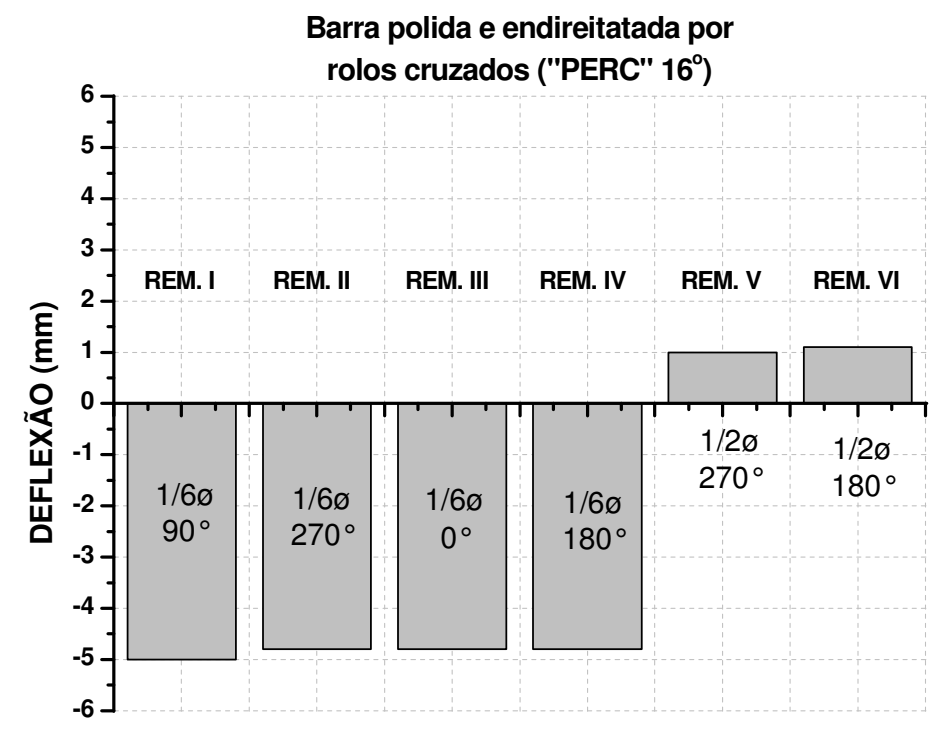

Figura 9: Deflexões apresentadas pela barra após o endireitamento por rolos cruzados ("PERC" $16^{\circ}$ ).

Na Figura 10 observam-se as tensões residuais e deflexões para a barra endireitada e polida por rolos cruzados ("PERC" com ângulo de $17^{\circ}$ ) na superfície da barra (remoções 1 a 4 ) apresentam caráter compressivo e da mesma forma que usando-se um ângulo de $16^{\circ}$ este não apresenta variações significativas ao longo do perímetro da barra e no núcleo da barra, remoções 5 e $6(1 / 2 \varnothing)$, o comportamento é trativo, comparando-se os valores de deflexão obtidos nos ensaios usando-se um ângulo de $17^{\circ}$ e $16^{\circ}$ nota-se que o ângulo de $16^{\circ}$ induz tensões mais compressivas na superfície e menos trativas considerando $1 / 2 \varnothing$ do que usando-se um ângulo de endireitamento e polimento de $17^{\circ}$.

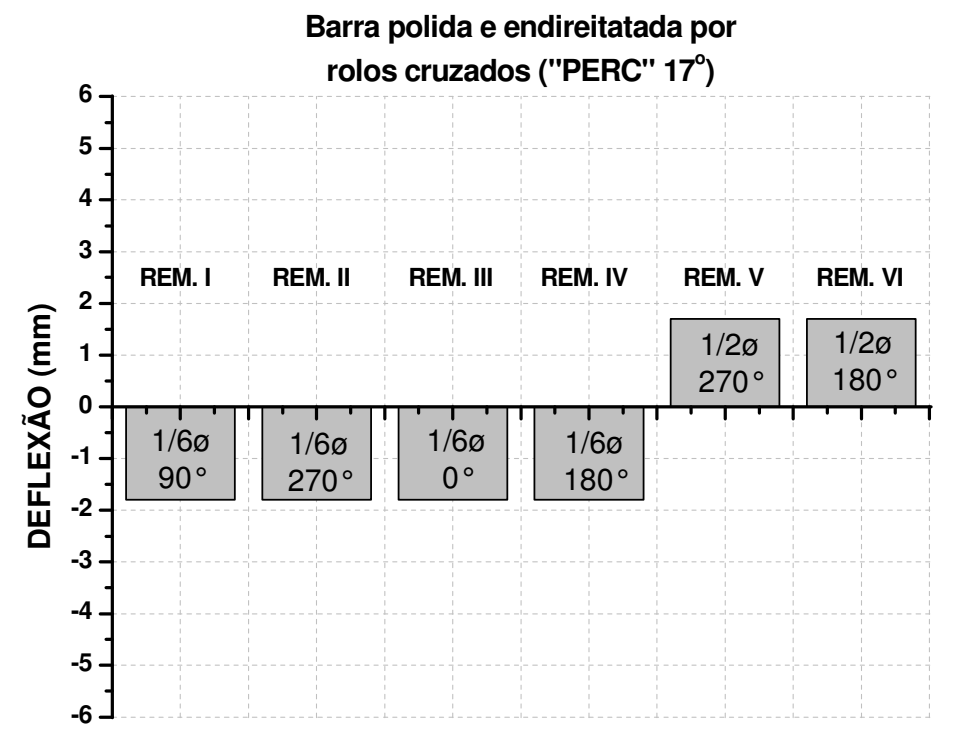

Figura 10: Deflexões apresentadas pela barra após o endireitamento por rolos cruzados ("PERC" $17^{\circ}$ ). 


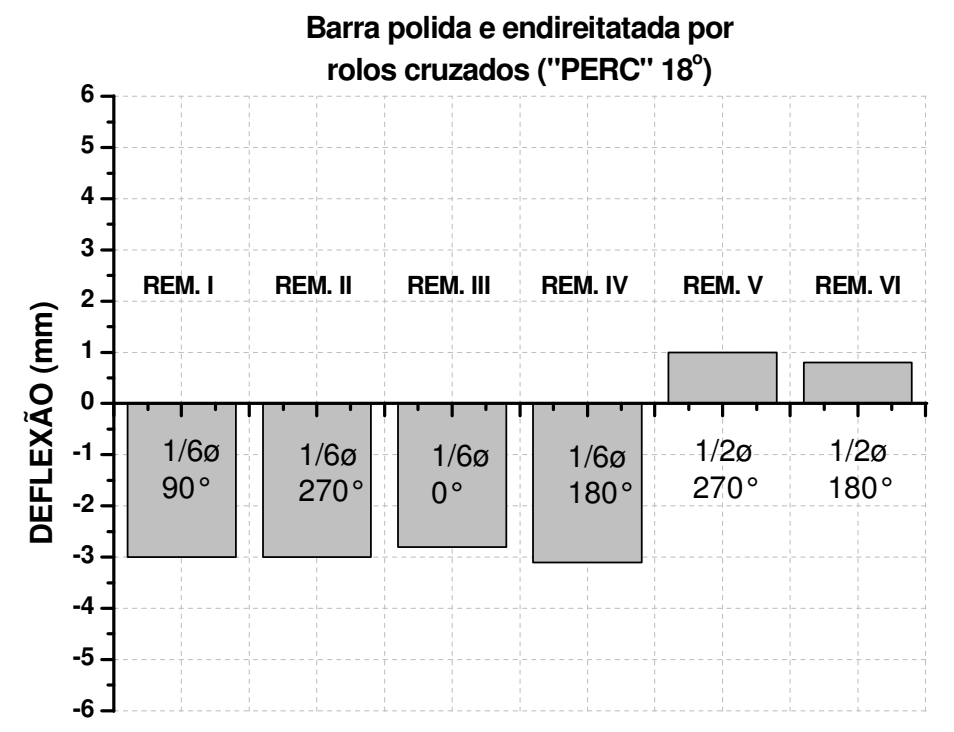

Figura 11: Deflexões apresentadas pela barra após o endireitamento por rolos cruzados ("PERC" 18º).

Na Figura 11 observa-se o comportamento apresentado pela barra com ângulo de endireitamento e polimento por rolos cruzados ("PERC") com ângulo de $18^{\circ}$, da mesma forma que os resultados de ângulos diferentes para esta etapa do processo, o comportamento é compressivo na superfície e trativo considerando $1 / 2 \varnothing$ da barra. Comparando-se os resultados apresentados pelo ângulo de "PERC" $18^{\circ}$ com 0 ângulo de "PERC" $16^{\circ}$ nota-se um nível menos compressivo na superfície da barra e um comportamento trativo em $1 / 2 \varnothing$ da barra semelhante ao apresentado pelo ângulo de "PERC" $16^{\circ}$.

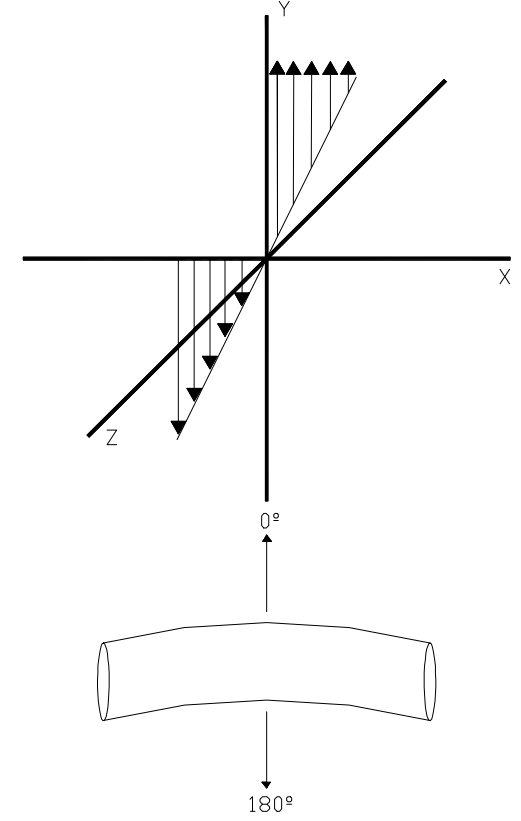

Figura 12: Tensões aplicadas durante o pré-endireitamento horizontal.
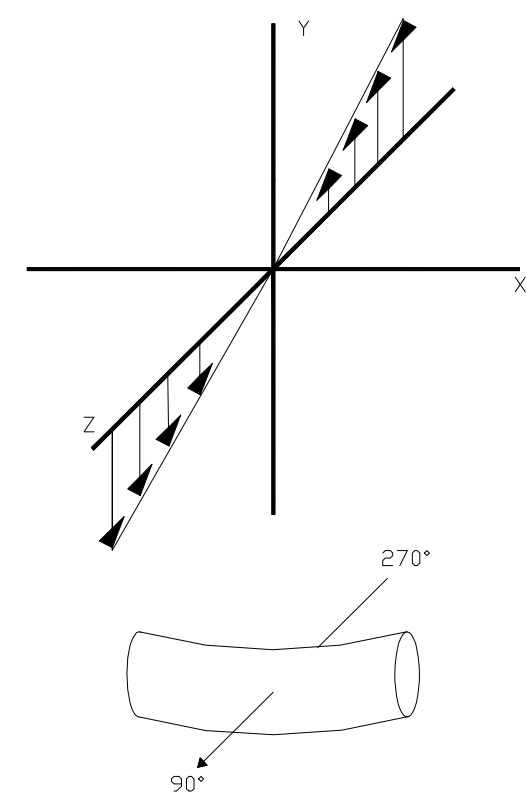

Figura 13: Tensões aplicadas durante o préendireitamento vertical. 


\section{Conclusões}

O método empregado mostrou ser simples e eficaz na determinação do comportamento das tensões residuais das barras após a trefilação. Após os ensaios conclui-se:

- O pré-endireitamento induz diferenças no comportamento de tensões residuais em relação a posição periférica do fio-máquina. Considerando $1 / 2 \varnothing$ do fio-máquina as tensões são trativas e o nível é baixo comparando-se com as tensões residuais superficiais.

- O jateamento induz tensões fortemente compressivas na superfície do fio-máquina, e considerando $1 / 2 \varnothing$ do fio-máquina as tensões podem ser trativas ou compressivas de acordo com a posição periférica do fio-máquina o quê corresponderia ao efeito do pré-endireitamento.

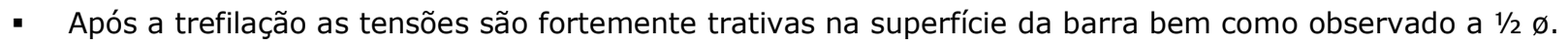

- Independente do ângulo de "PERC" as tensões são compressivas na superfície e trativas considerando 1/2 $\emptyset$.

- O ângulo de "PERC" de $16^{\circ}$ induz tensões mais compressivas na superfície das barras comparando-se com os outros ângulos ensaiados.

- O ângulo de "PERC" de $17^{\circ}$ apresenta um menor nível de tensões residuais na superfície comparando-se com os ângulos de $16^{\circ}$ e $18^{\circ}$ e também apresentou uma maior homogeneidade em relação as tensões residuais na superfície e a $1 / 2 \varnothing$ da barra. Por outro lado o ângulo de $16^{\circ}$ apresentou as maiores diferenças entre a superfície e $1 / 2 \varnothing$ da barra.

- O ângulo de "PERC" de $18^{\circ}$ apresentou um comportamento semelhante comparando-se com os outros ângulos de "PERC", porém, o ângulo de "PERC" $18^{\circ}$ induz tensões menos compressivas na superfície comparando-se com o ângulo de $16^{\circ}$. Por outro lado o ângulo de "PERC" $18^{\circ}$ apresenta um comportamento mais compressivo na superfície comparando-se com o ângulo de $17^{\circ}$.

\section{Agradecimentos}

Agradecemos ao CNPq, FINEP e CAPES pelo financiamento do projeto.

\section{Referências}

AKIKAZU, N.; TAKAAKI, Y.; MASAZUMI, K.; MOTOO, A.; WATARU, S.; KAZUNARI, Y. 2001. Behavior of residual stress and drawing stress in conical-type die and circle-type die drawing by FEM simulation and experiment. Wire Journal International, 34(8):72-80.

ASAKAWA, M.; SASAKI, W.; SHISHIDO, S. 2002. Effect of die approach geometry and bearing length on residual stress after bar drawing. Wire Journal International, 35(10):68-72.

ATIENZA, J.M.; ELICES, M. 2004. Influence of residual stresses in the stress relaxation of cold drawn wires. Materials and Structures, 37:301-304. 
DIETER, G. 1986. Metalurgia mecânica. Rio de Janeiro, Guanabara Dois, 653 p.

KENNEDY, D.M.; VAHEY, J.; HANNEY, D. 2005. Micro shot blasting of machine tools for improving surface finish and reducing cutting forces in manufacturing. Materials and Design, 26:203-208.

KLEIN, D.; THOBEN, K.-D.; NOWAG, L. 2006. Using indicators to describe distortion along a process chain. Materialwissenschaft und Werkstofftechnik, 37(1):19-22.

LU, J. 1996. Handbook of measurement of residual stresses. França, SEM, Inc. Senlis, 238 p.

METZ, M.; SANTOS, C.; ROCHA, A. 2007. Análise qualitativa das tensões residuais longitudinais em barras trefiladas de aço SAE 1045 através do método slliting. In: $8^{\circ}$ Congresso Iberoamericano de Engenharia Mecânica, Cusco, 2007. Anais... Cusco. P. 1213-1220.

WALTON, H.W. 2002. Deflection methods. In: G.E. TOTTEN; M.A.H. HOWES; T. INOUE, Handbook of Residual Stress and Deformation of Steel. Materials Park, ASM International, p. 89- 98.

WANG, Z.; GONG, B. 2002. Residual stress in the forming of materials. In: G.E. TOTTEN; M.A.H. HOWES; T. INOUE, Handbook of residual stress and deformation of steel. Materials Park, ASM International, p. 141-149.

WU, B.J.; CHAN, L.C.; LEE, T.C.; AO, L.W. 2000. A study on the precision modeling of the bars produced in two cross-roll straightening. Journal of Materials Processing Technology, 99:202-206.

$\mathrm{ZOCH}, \mathrm{H}$. -W. 2006. From single production step to entire process chain - the global approach of distortion engineering. Materialwissenschaft und Werkstofftechnik, 37(1):6-10.

Submissão: $24 / 07 / 2008$

Aceite: $26 / 09 / 2008$ 